\title{
An Experimental Study on Unit Side Resistance of Gaziantep Limestone
}

\author{
Volkan KALPAKCI ${ }^{1}$ \\ Islam TABUR ${ }^{2}$
}

\begin{abstract}
In this study, the correlation between the uniaxial compressive strength and unit side resistance of Gaziantep limestone was investigated experimentally for dry and fully saturated conditions. The results were compared with the methods given in the literature which correlate these two parameters. The linear correlations significantly overestimated the measured side resistance values for all tests while the non-linear methods generally overestimated the unit side resistance under fully saturated conditions but provided a reasonable estimation for dry samples. As a result, a linear correlation and non-linear correlation ranges for estimating the unit side resistance of such limestones were also suggested.
\end{abstract}

Keywords: Limestone, side resistance, rock, strength, correlation.

\section{INTRODUCTION}

Construction of rock-socketed piles is a preferable method in geotechnical engineering especially in case of an available rock layer at a reasonable depth below foundation. Generally, a higher bearing capacity is provided by such piles besides significantly smaller settlements as compared to those of floating piles. The magnitude of bond strength between concrete and rock surface, namely the unit side resistance of rock $\left(\mathrm{q}_{\mathrm{s}}\right)$, is a key factor in determining the bearing capacity of such piles. For this reason, there are various studies conducted for estimating the unit side resistance of rocks. Generally, the unit side resistance of rocks was correlated with their uniaxial compressive strength $\left(\sigma_{c}\right)$ in these studies. The correlations are generally classified in two groups as linear and non-linear correlations.

\footnotetext{
Note:

- This paper has been received on August 22, 2019 and accepted for publication by the Editorial Board on March 2, 2020.

- Discussions on this paper will be accepted by September 30, 2021.

- https://doi.org/10.18400/tekderg.608631

1 Hasan Kalyoncu University, Civil Engineering Department, Gaziantep, Turkey volkan.kalpakci@hku.edu.tr - https://orcid.org/0000-0002-5277-795X

2 Hasan Kalyoncu University, Civil Engineering Department, Gaziantep, Turkey islam.tabur@std.hku.edu.tr - https://orcid.org/0000-0003-0752-4205
} 
The linear correlations are in the general form of Eq. (1) where " $\mathrm{A}$ " is the linear correlation coefficient and dependent on the rock type. The equations suggested by [1], [2], [3] and [4] may be given as examples of such linear correlations.

$q_{s}=A x \sigma_{c}$

On the other hand, the non-linear correlations are in the general form of Eq. (2) where "C" and " $b$ " are coefficients dependent on the rock type. The relationships provided by [5], [6], [7], [8], [9], [10], [11] and [12] may be listed as examples of such non-linear correlations.

$q_{s}=C x \sigma_{c}^{b}$

Alternatively; in some studies such as [13] and [14], the rock mass parameters and socket roughness were also included in these correlations. However, these methods were not considered during assessment of the results of this study since the experiments of this research were performed on intact samples with smooth socket interfaces. Additionally, in a recent study by [15], the bearing capacity of rock-socketed piles in 4 different cities of Turkey was investigated through pile load tests.

Gaziantep, the eighth biggest city with leading trade capacity and highest population growth rate in its region, is located in the south-eastern part of Turkey. Generally, the soil profile of the city is composed of a surficial loose soil layer underlied by Gaziantep limestone. As a result, the use of rock socketed piles has become a popular solution for most of the recently built structures during the rapid construction of the city in the past decade. However, Gaziantep limestone is a chalky and clayey, porous soft rock as it was explained in detail in [16]. As a result of this fact, Gaziantep limestone becomes saturated easily which results in significant reduction of the uniaxial compressive strength $\left(\sigma_{c}\right)$ of Gaziantep limestone upon saturation which was also verified by [17]. The possible reasons of strength reduction observed in similar porous soft rocks upon water interaction were discussed by [18] and it was concluded that water saturation reduced the yield stress and failure strength of equivalent solid matrix due to a decrease in the capillary force of the liquid contact and the softening of the general rock structure.

Based on this fact; in this research it was aimed to investigate the relation between the unit side resistance and uniaxial compressive strength of Gaziantep limestone under dry and fully saturated conditions through an experimental study. For this purpose, firstly an unconfined compression testing machine was modified to perform these tests in laboratory scale. Then, 24 limestone blocks were taken from a quarry site in Gaziantep. Each block was separated into two adjacent parts and one part was tested under dry conditions while the other part was tested under fully saturated conditions. As a result of this study, a linear correlation and upper bound and lower bound curves as a non-linear correlation range were suggested for estimating the unit side resistance of Gaziantep limestone. Moreover, the test results were compared with the selected methods from the literature. These evaluations have revealed that especially the linear correlations were significantly overestimating the test data while the non-linear methods generally provided a reasonable estimation for dry samples but overestimated the unit side resistance under fully saturated conditions. 


\section{EXPERIMENTAL STUDY}

The experiments of this study were conducted in the soil mechanics laboratory of Hasan Kalyoncu University. As the first step of the experimental study, 24 limestone blocks having dimensions of 300x300x150mm (WidthxLengthxHeight) were taken from different places of a quarry site in Gaziantep. After assigning a number to each block; the blocks were cut into two adjacent parts having equal dimensions of $150 \times 300 \times 150 \mathrm{~mm}$ (WidthxLengthxHeight) making a total of 48 limestone blocks. In this way, it was aimed to have a dry and a fully saturated test result for each block. Then, a NX size cylindrical sample $(\mathrm{D}=54.7 \mathrm{~mm}$ ) was extracted from the middle of each of the 48 blocks (Figure 1). All the tests conducted on limestone samples were done in accordance with the suggested methods in ISRM [19]. The cylindrical samples were first weighed and then oven-dried at least for 24 hours (until constant weight) at $105 \pm 3{ }^{\circ} \mathrm{C}$. After the drying procedure, uniaxial compression tests were done for the dry samples of each block. The height/diameter ratio of the samples were $\mathrm{H} / \mathrm{D}=150 / 54.7=2.74$ and the loading rate was selected as $0.7 \mathrm{MPa} / \mathrm{s}$ from the range given in [19] as $0.5-1.0 \mathrm{MPa} / \mathrm{s}$. As a result, the uniaxial compressive strength of each dry sample from each block was determined.

The rest of the samples were soaked under water and weighed each day until constant weight (to nearest $0.01 \mathrm{~g}$ ), to ensure the fully saturation of the samples. A representative set of measurements is presented in Table 1. As it can be seen from this table, all the samples had become fully saturated in a week. After full saturation, the uniaxial compressive strengths of these samples were determined experimentally applying the same testing procedure described for dry samples. As a result, the uniaxial compressive strength of each sample from each block was determined for fully saturated condition. Additionally, some basic properties of the tested samples like porosity, water absorption capacity, dry and fully saturated unit weights were also determined during these tests in accordance with the testing procedures suggested in [19].

Upon completion of the uniaxial compression tests, the holes at the middle of the blocks which were drilled during the extraction of the cylindrical samples were filled with a concrete having 28 days characteristic compressive strength of 30MPa. CEM I 42.5 cement class was used for concrete production and the characteristic compressive strength was determined according to ASTM C39 [20] standard. All the rock blocks were soaked under water for 28 days to obtain the target compressive strength of the infilled concrete. The upper and lower ends of the cylindrical concrete core was levelled with a suitable cutter before testing in order to obtain a plane loading surface. After soaking procedure, the unit side resistance tests were executed for samples under fully saturated conditions while the remaining blocks were tested after completely dried in the oven. Here it should be mentioned that the soaking procedure followed for these tests may not fully simulate the situation for dry condition at site. Nevertheless, same procedure was applied for both dry and saturated samples to ensure having similar compressive strengths for infilled concrete to be able to obtain comparable side resistance values. The infilled concrete was intentionally selected to have a higher compressive strength than the highest uniaxial compressive strength value obtained for the tested limestone samples in order to ensure the failure of the surface between concrete and rock to be controlled by the side resistance of rock but not by the side cohesion of the concrete as it was also discussed in [21], [22] and [23]. 


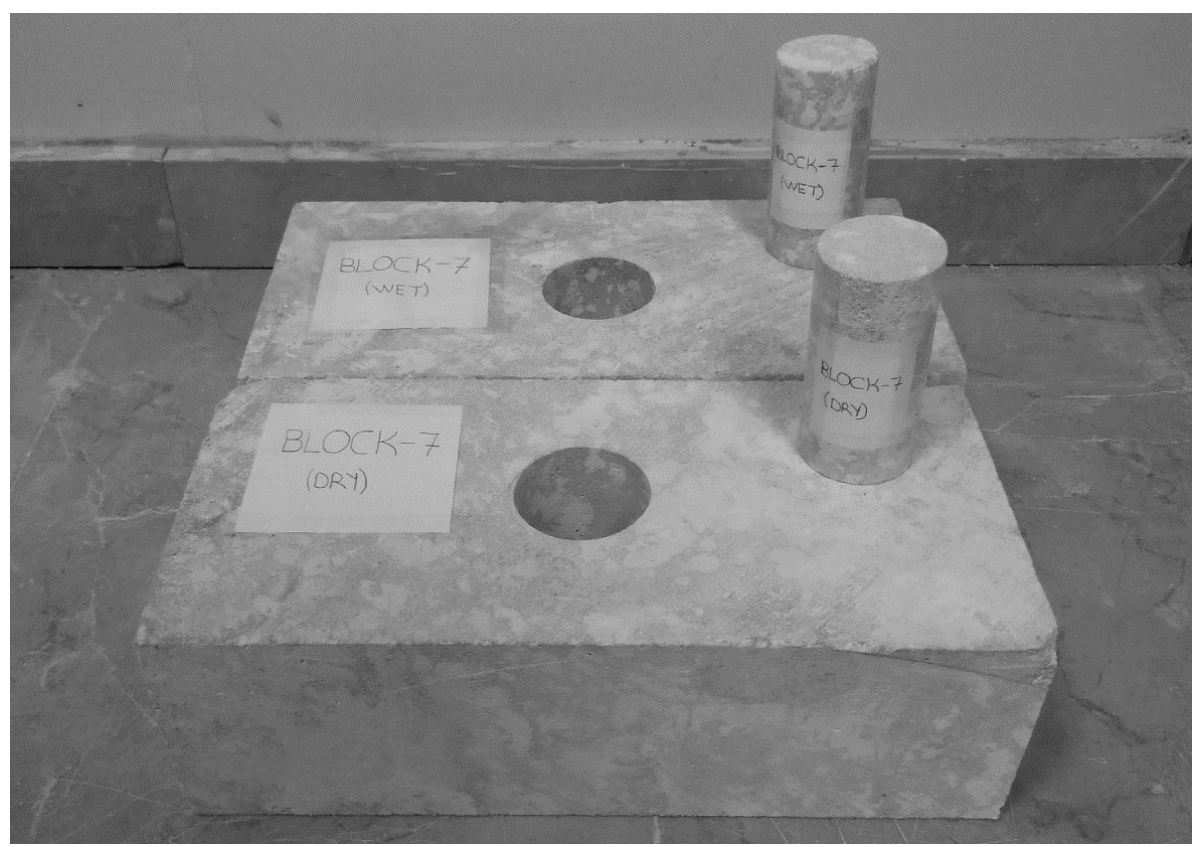

Figure 1 - Adjacent parts of Block-7 and NX size samples taken from the middle

Table 1 - Representative set of measurements for saturation

\begin{tabular}{cc|ccccccc}
\hline & $1^{\text {st }}$ day & $2^{\text {nd }}$ day & $3^{\text {rd }}$ day & $4^{\text {th }}$ day & $5^{\text {th }}$ day & $6^{\text {th }}$ day & $7^{\text {th }}$ day & $8^{\text {th }}$ day \\
\hline Block & Completely Dry & \multicolumn{7}{|c}{ Saturated Weight $(\mathrm{g})$} \\
\hline Block 1 & 613,87 & 737,78 & 740,68 & 742,51 & 744,03 & 744,82 & 744,82 & 744,82 \\
\hline Block 2 & 608,67 & 730,95 & 734,42 & 734,45 & 734,50 & 736,56 & 737,32 & 737,33 \\
\hline Block 3 & 752,61 & 838,65 & 840,52 & 840,98 & 841,57 & 842,13 & 842,17 & 842,18 \\
\hline Block 4 & 755,25 & 836,45 & 838,06 & 838,82 & 840,45 & 840,79 & 840,87 & 840,87 \\
\hline Block 5 & 602,08 & 726,61 & 730,10 & 731,73 & 732,18 & 733,96 & 734,16 & 734,17 \\
\hline Block 6 & 597,27 & 721,57 & 725,33 & 726,73 & 728,08 & 729,84 & 730,00 & 730,00 \\
\hline
\end{tabular}

Since the cylindrical sampler had a side wall thickness of $3.00 \mathrm{~mm}$, the diameter of the holes opened to take NX size samples and later infilled with concrete were $D_{\text {IC }}=60.7 \mathrm{~mm}$ while the heights of the holes were equal to the heights of the blocks $(\mathrm{H}=150 \mathrm{~mm})$. An unconfined compression testing machine was modified for determination of the unit side resistance of limestone blocks. A circular loading piston having a slightly smaller diameter $\left(D_{L P}=60 \mathrm{~mm}\right)$ than that of the infilled concrete core $\left(\mathrm{D}_{\mathrm{IC}}=60.7 \mathrm{~mm}\right)$ was mounted to the loading system to load the concrete core in the rock block axially without any friction. Also, a stiff steel box with a hole in the middle having a diameter slightly wider than that of the concrete core $\left(D_{h}\right.$ $=65 \mathrm{~mm}$ ) was put under the block to allow the slip displacement of the concrete cylinder in 
the rock block (as illustrated in Figure 2). The steel box had a slightly larger surface (WidthxLength $=170 \times 340 \mathrm{~mm}$ ) than the base of the rock block (WidthxLength = $150 \times 300 \mathrm{~mm}$ ) to prevent any motion of the rock block during testing. The axial loads were recorded by a $100 \mathrm{kN}$ capacity load cell with a sensitivity of $0.001 \%$. A displacementcontrolled testing procedure was applied during the experiments. In order to determine the suitable displacement rate, tests were conducted on control blocks for both dry and fully saturated conditions for displacement rates changing between $0.001-0.1 \mathrm{~mm} / \mathrm{s}$. Since the obtained side resistance values were changing within a very narrow band $(\approx \pm 5 \%)$ for the tested displacement rate range, the displacement rate was selected as $0.01 \mathrm{~mm} / \mathrm{s}$. This rate was both slow enough to observe the experiment and fast enough to complete it in a reasonable duration. The displacement of the rock block was also measured by a LVDT having $25 \mathrm{~mm}$ axial displacement capacity. The test setup is presented schematically in Figure 2 and a sample view of the test is given in Figure 3. All experiments were continued after failure, to ensure that the sliding had occurred along the contact surface between limestone and concrete. An example of the observed slip surfaces is given in Figure 4 in which the slipped concrete core from rock block can be clearly seen.

The unit side resistance of each block was determined by dividing the ultimate failure load to the inner surface contact area of each hole at the time of failure. A sample test data is given in Figure 5. As it can be observed from this figure, the applied axial load $(F)$ was recorded with the corresponding slip displacement $(\Delta)$ and the unit side resistance was calculated by dividing ultimate load " $F$ " to the inner surface contact area which is defined as the inner surface area of the cylinder in contact with concrete core at the time of failure. For instance, the ultimate load was recorded as $\mathrm{F}=13199 \mathrm{~N}$ for $\Delta=8.635 \mathrm{~mm}$ slip displacement for the test data presented in Figure 5. For this test, the unit side resistance was calculated in Eq. (3) as:

$q_{s}=\frac{F}{\pi x D_{I C} x(H-\Delta)}=\frac{13199}{\pi \times 60.7 x(150-8.635)}=0.49 \mathrm{MPa}$

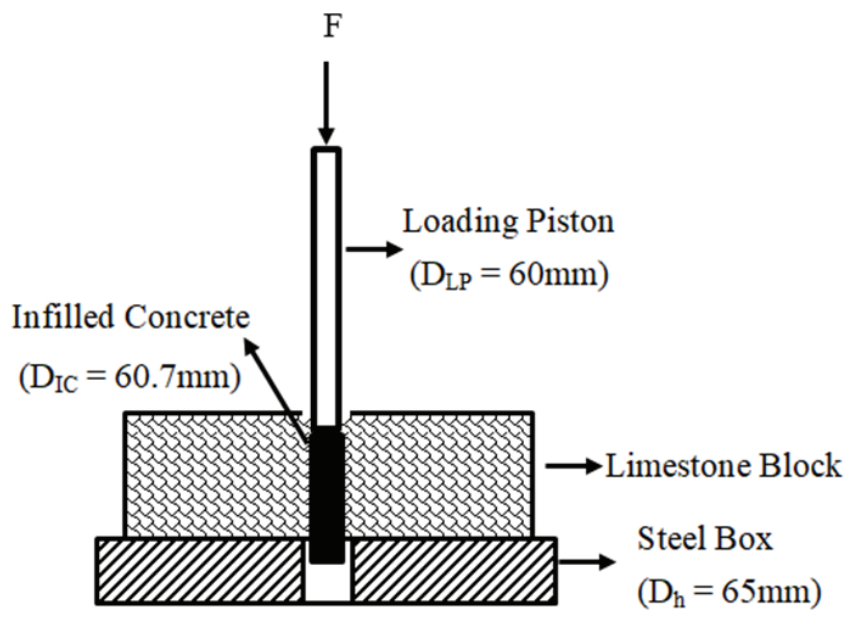

Figure 2 - Schematic cross-sectional view of test setup 


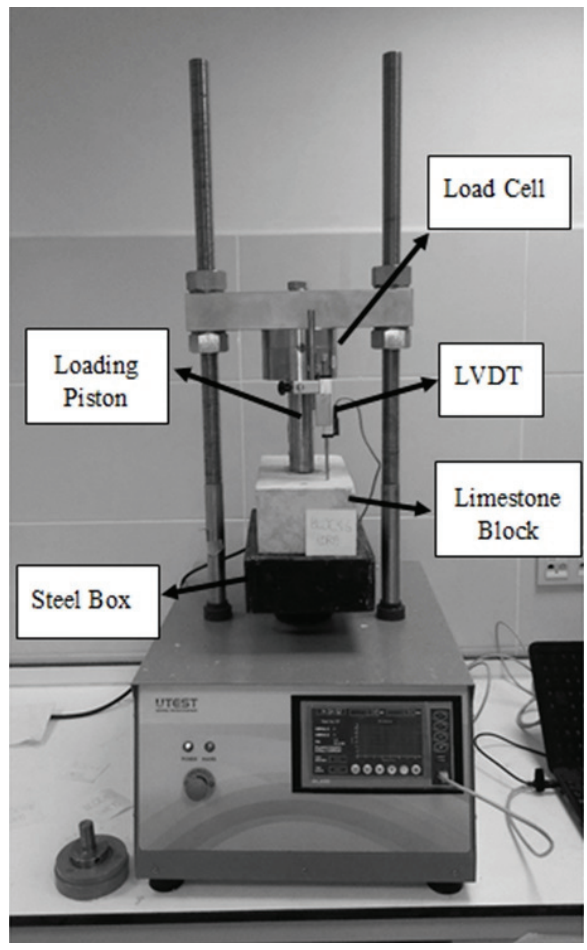

Figure 3 - A sample view of test setup

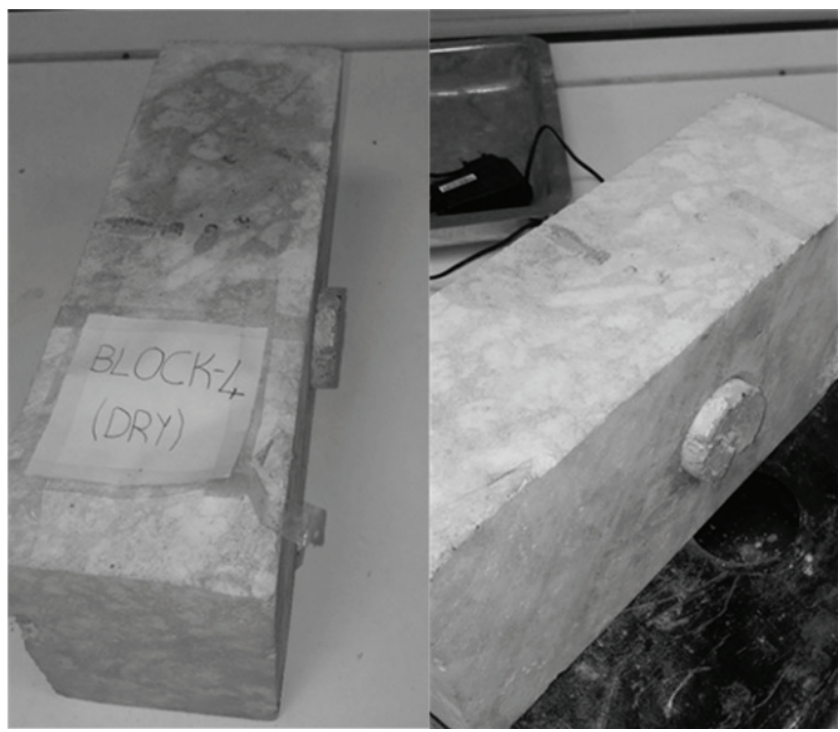

Figure 4 - A sample view from sliding failure of concrete core 


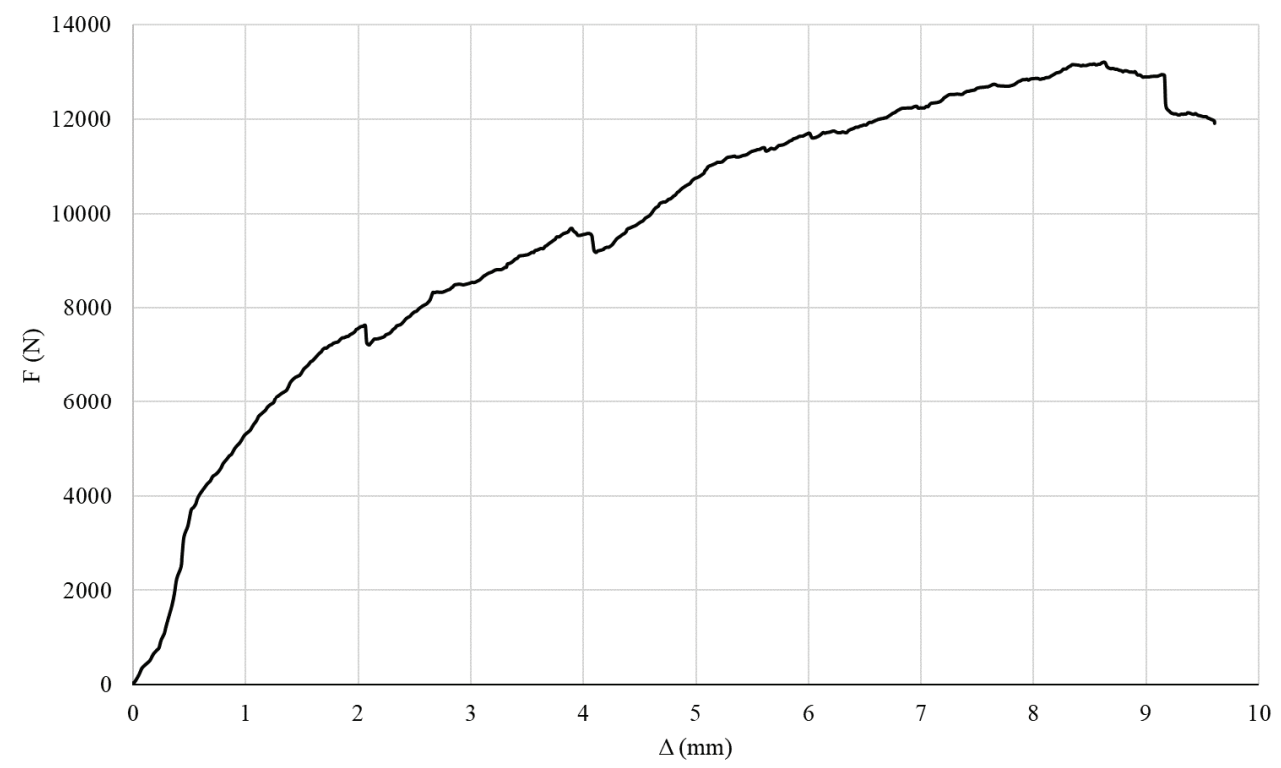

Figure 5 - Sample test data for Block 6 (Fully saturated condition)

\section{RESULTS AND DISCUSSIONS}

\subsection{General Evaluation of the Test Results}

The experiments conducted within this study have revealed that the dry unit weights of the samples were changing between $\gamma_{\text {dry }}=16.62-21.02 \mathrm{kN} / \mathrm{m}^{3}$, while the saturated unit weights of the samples were between $\gamma_{\text {sat }}=20.32-23.40 \mathrm{kN} / \mathrm{m}^{3}$. The porosity of the tested samples was in the range of $\mathrm{n}=24-38 \%$ while the water absorption capacity was between $\mathrm{w}=11-$ $22 \%$ by weight. The uniaxial compressive strengths of the dry samples were within the range of $\sigma_{\mathrm{c}}=15.65-22.07 \mathrm{MPa}$ while those of the fully saturated samples were between $\sigma_{\mathrm{c}}=10.00$ - 12.97 MPa. The reduction in the uniaxial compressive strength of Gaziantep limestone between dry and fully saturated conditions was in the range of $36.10-42.86 \%$. These results were within a comparable range with the results presented in [17].

The experimental results have revealed that the unit side resistances of the completely dry samples were in between $\mathrm{q}_{\mathrm{s}}=0.78-1.45 \mathrm{MPa}$ for a rock uniaxial compressive strength range of $\sigma_{\mathrm{c}}=15.65-22.07 \mathrm{MPa}$. As expected, the unit side resistances of the fully saturated samples were seen to decrease significantly as compared to those of dry samples similar to the behaviour observed for uniaxial compressive strength values. The unit side resistances of the fully saturated samples were varying in the range of $\mathrm{q}_{\mathrm{s}}=0.36-0.80 \mathrm{MPa}$ for a uniaxial compressive strength interval of $\sigma_{\mathrm{c}}=10.00-12.97 \mathrm{MPa}$.

While the percent reduction in the uniaxial compressive strength of Gaziantep limestone under fully saturated condition as compared to dry condition was in a narrow band of 36.10 
$-42.86 \%$, the percent reduction in the unit side resistance was changing in a wider range $(23.96-64.23 \%)$. This fact was attributed to the variability in the inner surface structure of each tested block. Although all of the holes had a smooth and intact contact surface with concrete core, each had a different inner surface structure due to the chalky, clayey and porous composition of Gaziantep limestone as discussed previously. Hence, the observed side resistance reduction due to saturation was not directly comparable with the approximate $40 \%$ reduction in the uniaxial compressive strength of Gaziantep limestone upon saturation, as expected. The results of the uniaxial compression and unit side resistance experiments were summarized in Table 2.

\subsection{Discussion of the Results}

As explained before, the main aim in this study was to investigate the correlation between the unit side resistance and uniaxial compressive strength of Gaziantep limestone under dry and fully saturated conditions. The relationships given in the literature which correlate the uniaxial compressive strength of rocks $\left(\sigma_{c}\right)$ with their unit side resistance $\left(\mathrm{q}_{\mathrm{s}}\right)$ may be divided into two main groups as linear and non-linear relationships as it was briefly discussed in the introduction. In this part of the study, the experimental results were compared with selected linear and non-linear correlations and discussions were made based on these comparisons.

\subsubsection{Comparison of Experimental Results with Linear Correlations}

The linear correlations suggested by [1-4] were in the general form given in Eq. (1) and the coefficient " $A$ " changed between $0.15-0.30$ (Table 3 ). The linear correlations suggested by [1], [2] and [4] were obtained by site measurements on different local rocks (limestone and/or weak rock) while the correlation given by [3] was developed for a design regulation based on a larger database of measurements from different rock sites. It should here be stated that, some of these listed methods may not be originally suggested directly to estimate the unit side resistance of the limestones similar to the ones tested in this study but nevertheless they were included in the evaluations to reveal the overestimation of these linear methods for the studied limestone samples. These linear relationships were plotted on Figure 6, together with the results obtained from this study. As it can be seen on this figure, even the method with the least coefficient [3] significantly overestimated unit side resistance of Gaziantep limestone both for dry and fully saturated conditions. This fact was also reported by [12] for a large database of unit side resistance values obtained from different types of limestones. As an alternative to the proposed methods, a new linear correlation was suggested in this study for estimating the unit side resistance of Gaziantep limestone from its uniaxial compressive strength as given in Eq. (4). As it was also plotted on Figure 6, the proposed correlation yields to an almost unbiased estimation with a correlation coefficient of $\mathrm{R}^{2}=0.77$. Additionally, $\mathrm{a}$ f-test was conducted to compare measured $\mathrm{q}_{\mathrm{s}}$ values with the predicted ones from the suggested regression equation. The test result had revealed that the predicted $\mathrm{q}_{\mathrm{s}}$ values had a meaningful correlation with the measured results within $95 \%$ confidence interval.

$q_{s}=0.056 x \sigma_{c}$ 
Table 2 - Results of the experimental study

\begin{tabular}{|c|c|c|c|c|c|}
\hline & & $\sigma_{\mathrm{c}}(\mathrm{Mpa})$ & $\mathrm{q}_{\mathrm{s}}(\mathrm{Mpa})$ & Reduction in $\sigma_{\mathrm{c}}(\%)$ & Reduction in $\mathrm{q}_{\mathrm{s}}(\%)$ \\
\hline \multirow{2}{*}{ Block 1} & Dry & 18.32 & 1.45 & \multirow{2}{*}{39.08} & \multirow{2}{*}{44.83} \\
\hline & Saturated & 11.16 & 0.80 & & \\
\hline \multirow{2}{*}{ Block 2} & Dry & 19.29 & 0.88 & \multirow{2}{*}{39.92} & \multirow{2}{*}{48.86} \\
\hline & Saturated & 11.59 & 0.45 & & \\
\hline \multirow{2}{*}{ Block 3} & Dry & 16.95 & 1.16 & \multirow{2}{*}{38.05} & \multirow{2}{*}{46.55} \\
\hline & Saturated & 10.50 & 0.62 & & \\
\hline \multirow{2}{*}{ Block 4} & Dry & 16.19 & 0.78 & \multirow{2}{*}{37.74} & \multirow{2}{*}{53.85} \\
\hline & Saturated & 10.08 & 0.36 & & \\
\hline \multirow{2}{*}{ Block 5} & Dry & 18.12 & 1.00 & \multirow{2}{*}{38.58} & \multirow{2}{*}{52.00} \\
\hline & Saturated & 11.13 & 0.48 & & \\
\hline \multirow{2}{*}{ Block 6} & Dry & 22.07 & 1.23 & \multirow{2}{*}{41.23} & \multirow{2}{*}{60.16} \\
\hline & Saturated & 12.97 & 0.49 & & \\
\hline \multirow{2}{*}{ Block 7} & Dry & 20.12 & 1.01 & \multirow{2}{*}{40.61} & \multirow{2}{*}{38.61} \\
\hline & Saturated & 11.95 & 0.62 & & \\
\hline \multirow{2}{*}{ Block 8} & Dry & 16.55 & 0.95 & 3027 & 50.53 \\
\hline & Saturated & 10.05 & 0.47 & 39.21 & 50.53 \\
\hline Ploct 0 & Dry & 17.34 & 0.83 & & \\
\hline Block 9 & Saturated & 10.65 & 0.38 & 38.58 & 54.22 \\
\hline Block 10 & Dry & 18.62 & 1.03 & 3707 & 3680 \\
\hline DIOCK 10 & Saturated & 11.55 & 0.65 & 31.91 & 30.09 \\
\hline Block 11 & Dry & 21.78 & 1.33 & 4114 & 4135 \\
\hline В10ск 11 & Saturated & 12.82 & 0.78 & 41.14 & 41.55 \\
\hline P1ol 12 & Dry & 15.65 & 0.82 & 3610 & 2027 \\
\hline Block 12 & Saturated & 10.00 & 0.58 & 36.10 & 29.21 \\
\hline Block 13 & Dry & 17.93 & 0.96 & 3876 & 2306 \\
\hline В10टर 13 & Saturated & 10.98 & 0.73 & 38.10 & 23.90 \\
\hline Block 14 & Dry & 17.33 & 1.02 & 3837 & 3627 \\
\hline Block 14 & Saturated & 10.68 & 0.65 & 38.31 & 30.21 \\
\hline Block 15 & Dry & 19.19 & 1.28 & 4028 & 5625 \\
\hline В10СК 15 & Saturated & 11.46 & 0.56 & 40.28 & 50.25 \\
\hline Block 16 & Dry & 16.56 & 1.03 & 3871 & 6117 \\
\hline Block 16 & Saturated & 10.15 & 0.40 & 38.11 & 01.17 \\
\hline Block 17 & Dry & 21.21 & 1.24 & 42.86 & 54.84 \\
\hline Block 17 & Saturated & 12.12 & 0.56 & 42.86 & 54.84 \\
\hline Block 18 & Dry & 19.89 & 1.28 & 3801 & 5156 \\
\hline & Saturated & 12.33 & 0.62 & 38.01 & 51.56 \\
\hline Block 19 & Dry & 17.49 & 1.10 & 4025 & 5636 \\
\hline Block 19 & Saturated & 10.45 & 0.48 & 40.25 & 56.36 \\
\hline Block 20 & Dry & 16.71 & 1.28 & 37.88 & 56.25 \\
\hline & Saturated & 10.38 & 0.56 & & \\
\hline Block 21 & Dry & 19.71 & 1.10 & 2705 & 3636 \\
\hline DIOCK 21 & Saturated & 12.23 & 0.70 & 37.95 & 36.36 \\
\hline Block 22 & Dry & 18.28 & 0.92 & 4065 & 43,48 \\
\hline Block 22 & Saturated & 10.85 & 0.52 & 40.65 & 43.48 \\
\hline Plock 23 & Dry & 20.25 & 1.40 & 3026 & 6257 \\
\hline DIOCK 23 & Saturated & 12.30 & 0.51 & 39.26 & 63.57 \\
\hline Block 24 & Dry & 18,11 & 1,23 & 3810 & 6423 \\
\hline В10ск 24 & Saturated & 11.21 & 0.44 & 38.10 & 04.23 \\
\hline
\end{tabular}


Table 3 - Summary of the linear correlations discussed in this study

\begin{tabular}{cc}
\hline Correlation & Reference \\
\hline$q_{s}=0.15 x \sigma_{c}$ & {$[3]$} \\
\hline$q_{s}=0.20 x \sigma_{c}$ & {$[2]$} \\
\hline$q_{s}=0.25 x \sigma_{c}$ & {$[4]$} \\
\hline$q_{s}=0.30 x \sigma_{c}$ & {$[1]$} \\
\hline$q_{s}=0.056 x \sigma_{c}$ & This Study \\
\hline
\end{tabular}

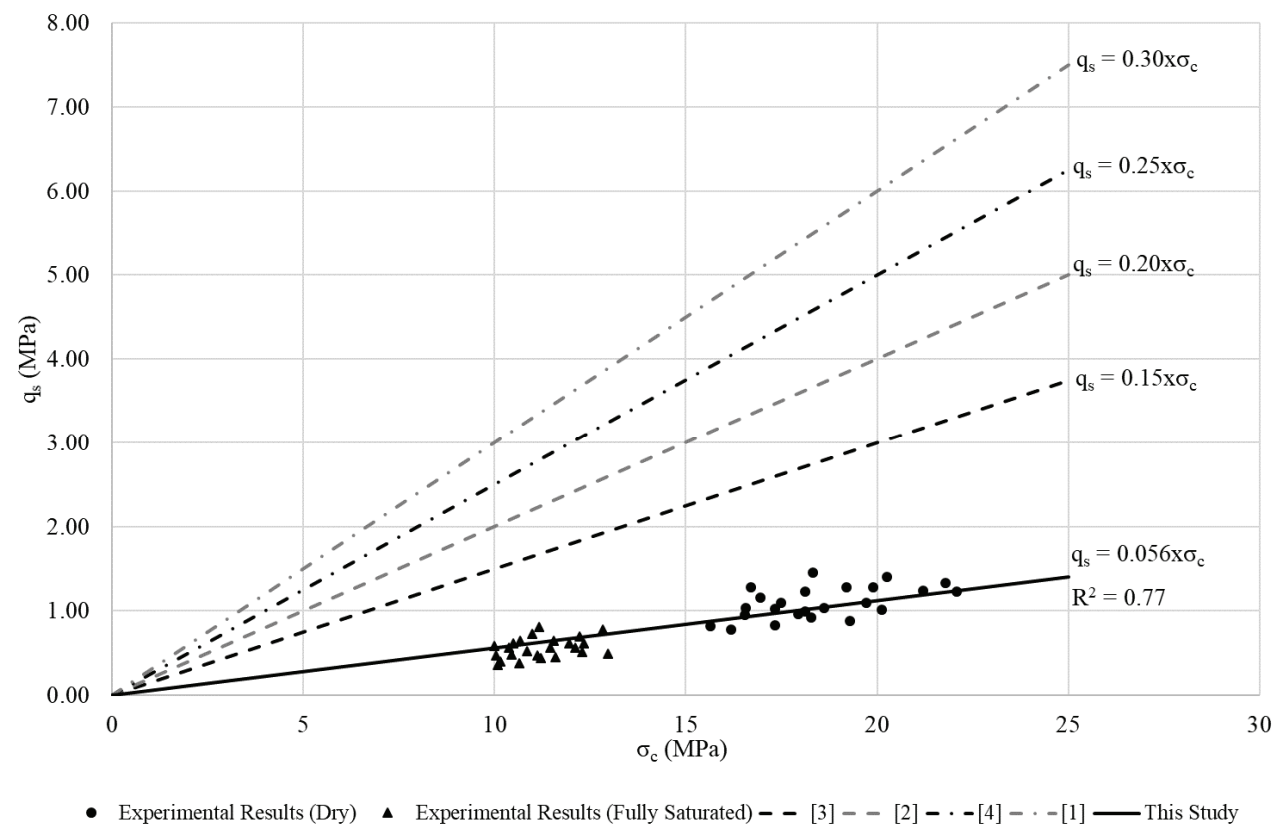

Figure 6 - Comparison of Test Results with Linear Correlations

\subsubsection{Comparison of Experimental Results with Non-Linear Correlations}

Among the non-linear correlations that may be found in the literature, the results of this study were compared with the methods either suggested by generally accepted standards or with the selected suitable ones during development of which a database containing data from different limestone measurements was utilized. These correlations are summarized in Table 4.

Among the selected correlations, [7] may be evaluated as an early example of such studies based on site experiments. Later, a more sophisticated non-linear correlation was developed by [9] especially for weak rocks by compiling the available literature information for shaft 
resistance of rock-socketed piles including the databases collected by [24], [25] and [8]. The correlation suggested by [10] was based on 25 load tests on drilled shafts. In the study of [11], the database which was once compiled by [13] was incorporated by the results of 47 load tests from 13 different limestone sites given by [26] and [27]. The non-linear correlation suggested by [12] was developed based on load test results of 63 rock-socketed piles almost half of which were obtained from limestone sockets.

Table 4 - Summary of the non-linear correlations discussed in this study

\begin{tabular}{|c|c|}
\hline Correlation & Reference \\
\hline$q_{s}=0.21 x \sqrt{\sigma_{c}}$ for $\sigma_{\mathrm{c}}>1.9 \mathrm{MPa}$ & [28] (After [7]) \\
\hline $\begin{array}{c}\frac{q_{s}}{P a}=b\left(\frac{\sigma_{c}}{P a}\right)^{0.5} \\
\mathrm{~b}=0.63, \mathrm{~Pa}=\text { Reference Pressure }(100 \mathrm{kPa})\end{array}$ & $\begin{array}{l}\text { [29] Lower bound } \\
\text { (After [10]) }\end{array}$ \\
\hline $\begin{aligned} & \frac{q_{s}}{P a}=b\left(\frac{\sigma_{c}}{P a}\right)^{0.5} \\
\mathrm{~b}=1.41, \mathrm{~Pa}= & \text { Reference Pressure }(100 \mathrm{kPa})\end{aligned}$ & $\begin{array}{l}\text { [29] Upper bound } \\
\text { (After [9]) }\end{array}$ \\
\hline $\begin{array}{c}\frac{q_{s}}{P a}=c\left(\frac{\sigma_{c}}{2 P a}\right)^{0.5} \\
\mathrm{c}=1 \text { (lower bound), } \mathrm{c}=2 \text { (mean), } \mathrm{c}=3 \text { (upper } \\
\text { bound) }\end{array}$ & {$[11]$} \\
\hline $\begin{array}{c}q_{s}=0.4014 x \sigma_{c}^{0.3411} \text { (For limestones) } \\
q_{s}=0.36 x \sigma_{c}^{0.36} \text { (For general) }\end{array}$ & {$[12]$} \\
\hline $\begin{array}{l}\left.q_{s}=0.10 x \sqrt{\sigma_{c}} \text { (Lower bound }\right) \\
\left.q_{s}=0.25 x \sqrt{\sigma_{c}} \text { (Upper bound }\right)\end{array}$ & This Study (Fully Saturated) \\
\hline $\begin{array}{l}\left.q_{s}=0.19 x \sqrt{\sigma_{c}} \text { (Lower bound }\right) \\
\left.q_{s}=0.35 x \sqrt{\sigma_{c}} \text { (Upper bound }\right)\end{array}$ & This Study (Dry) \\
\hline
\end{tabular}

In this manner, the results were firstly compared with the methods suggested in [28] and [29]. For rocks with a uniaxial compressive strength greater than $\sigma_{\mathrm{c}}>1,9 \mathrm{MPa}$, the correlation suggested by [7] was recommended by [28] for estimation of unit side resistance from uniaxial compressive strength of rock. On the other hand, the correlations suggested by [10] and [9] were recommended as lower and upper bound values respectively for estimation of unit side resistance in [29]. The test results were compared with these correlations in Figure 7. As it can be seen this figure, the suggestion of [28] and lower bound solution of [29] have given very close solutions. Both methods provided a reasonable lower bound estimation for dry samples. However, the unit side resistances of fully saturated samples were mostly overestimated by these methods. 


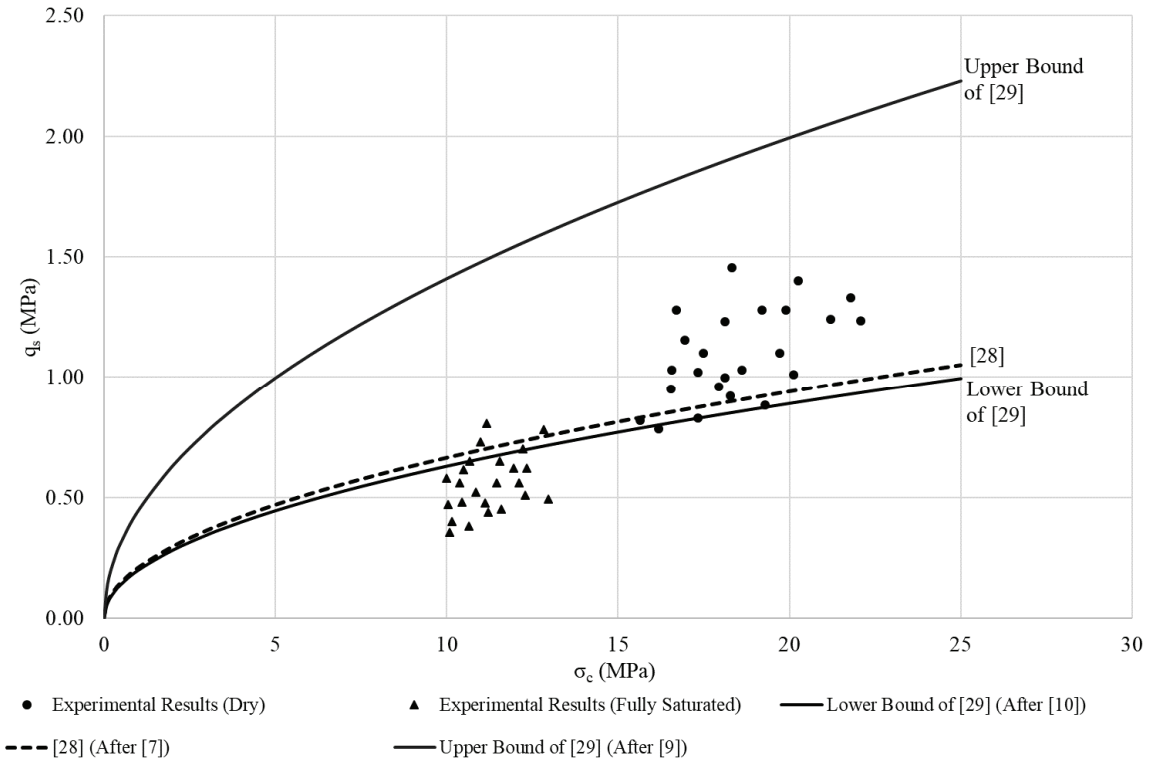

Figure 7 - Comparison of Test Results with [28] and [29]

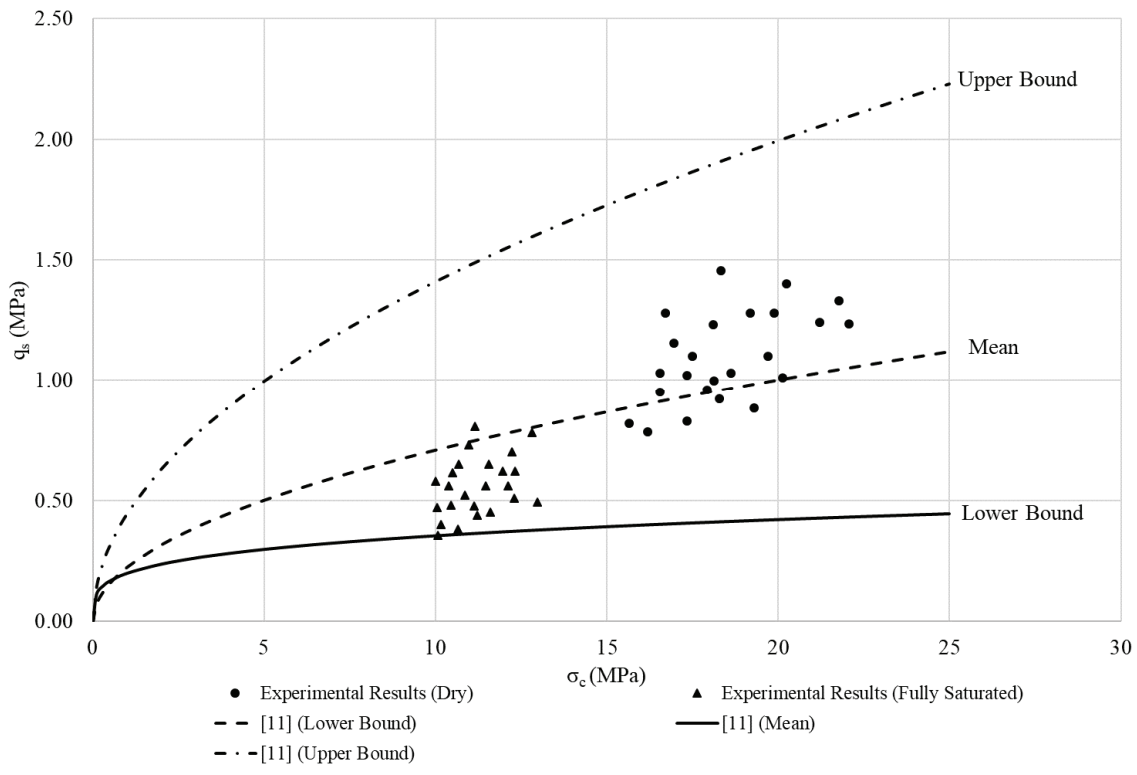

Figure 8 - Comparison of Test Results with [11] 
In a more recent correlation suggested by [11] lower bound, mean and upper bound solutions were suggested for estimation of unit side resistance. It should here be noted that the database utilized in the study of [11] contained a significant amount of data obtained from limestones. As it can be observed from Figure 8, the lower bound solution of the method suggested by [11] successfully covered even the lowest data obtained for fully saturated samples of this study. On the other hand, the curve for mean $(\mathrm{c}=2)$ had seemed to provide a more realistic estimation for unit side resistance of dry samples.

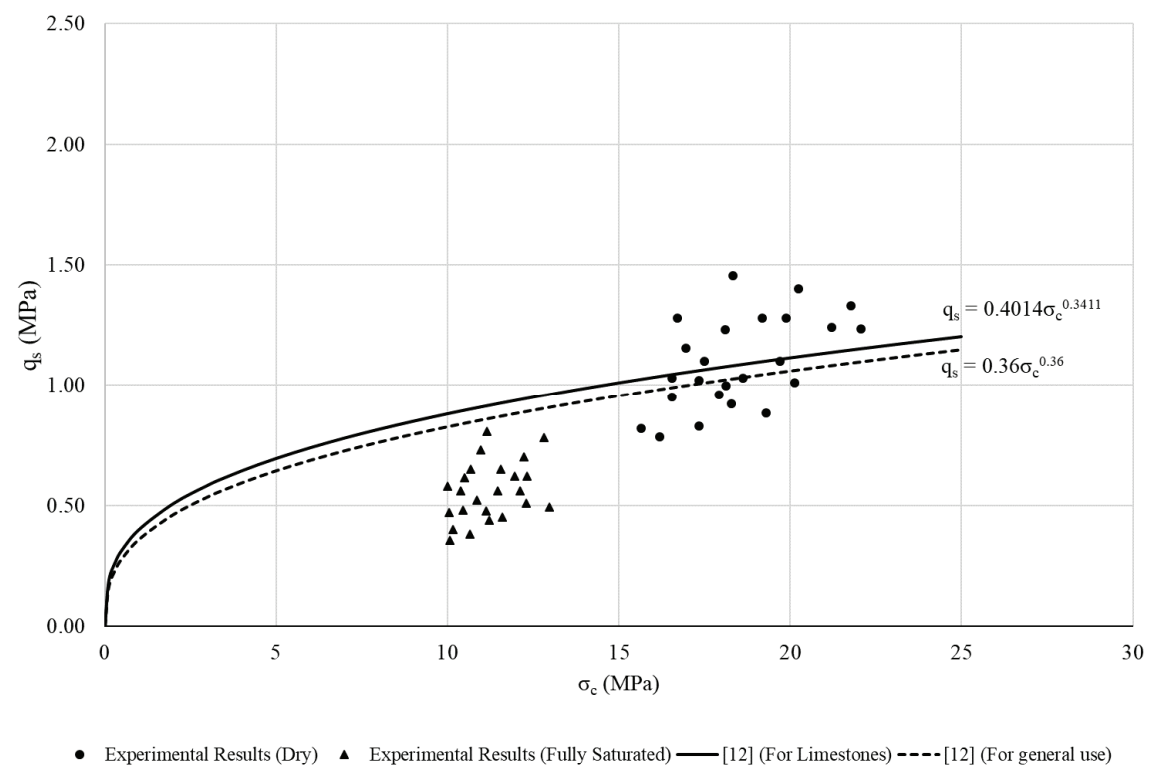

Figure 9 - Comparison of Test Results with [12]

In the study of [12], the side resistance data for various types of rocks obtained from the previous studies of various researchers were analysed in a combined manner and best-fit curves were suggested for different rock types. Among these correlations; the ones suggested for limestones and for general use which were obtained by generating a best-fit to the data only for limestones and to the combined data respectively were utilized for evaluation. Both curves have given a reasonable estimation for unit side resistance under dry conditions as it can be seen in Figure 9. However, the unit side resistance of Gaziantep limestone for fully saturated samples was overestimated by the suggested correlations.

Finally, lower bound and upper bound solutions were suggested as non-linear correlations in this study for fully saturated (Figure 10) and dry conditions (Figure 11), for estimation of the unit side resistance of Gaziantep limestone from its uniaxial compressive strength (see Eq. (5), Eq. (6), Eq. (7) and Eq. (8)). 


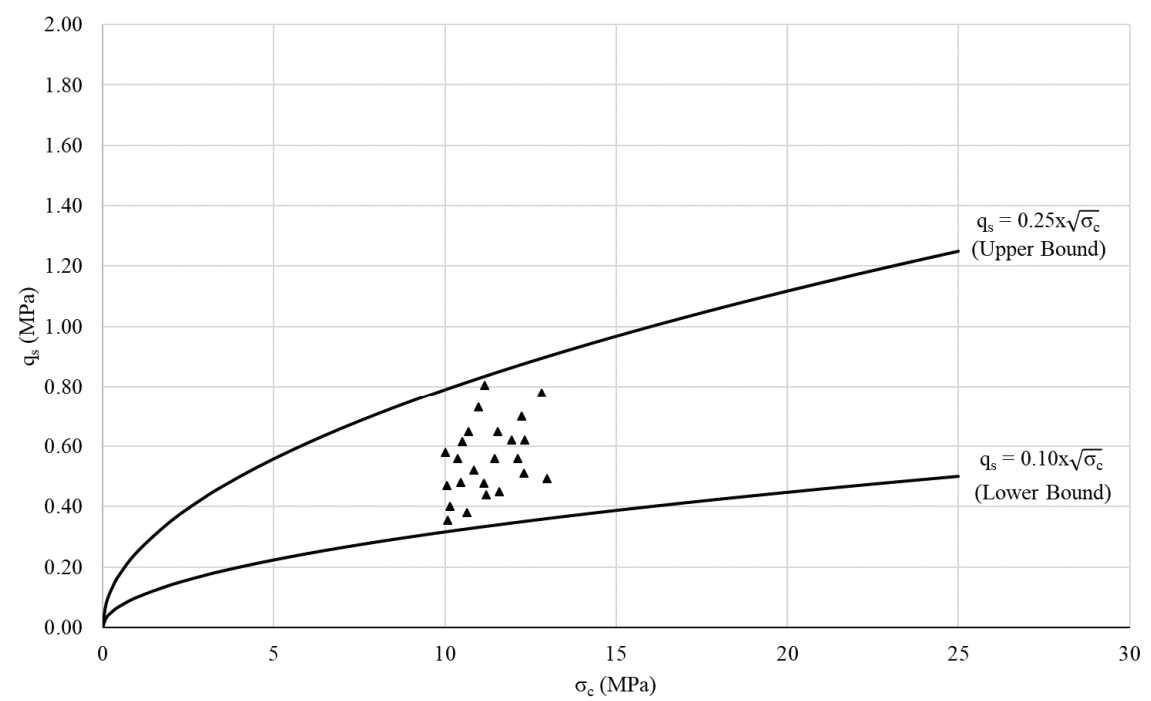

^ Experimental Results (Fully Saturated) — This Study (Lower Bound) —This Study (Upper Bound)

Figure 10 - Lower bound and upper bound curves for Gaziantep Limestone (Fully Saturated)

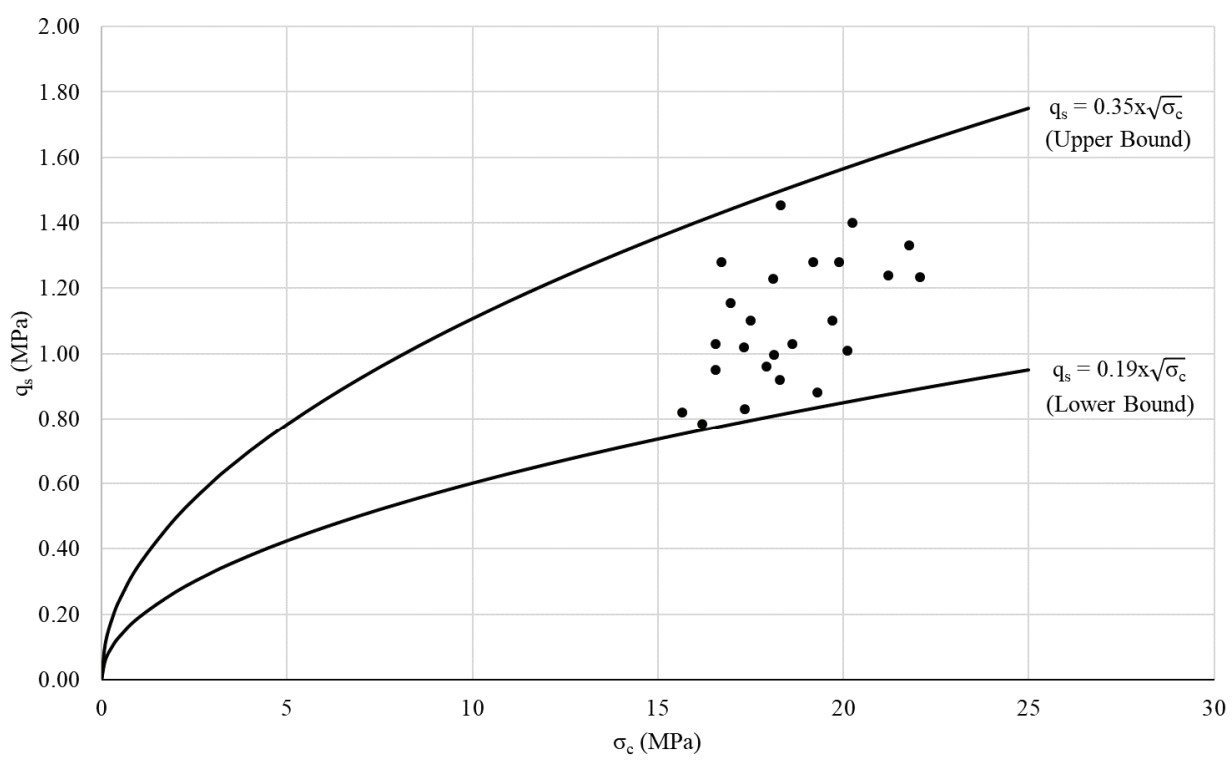

- Experimental Results (Dry) — This Study (Lower Bound) — This Study (Upper Bound)

Figure 11 - Lower bound and upper bound curves for Gaziantep Limestone (Dry) 
$q_{s}=0.10 x \sqrt{\sigma_{c}}$ (Lower bound solution for Gaziantep Limestone, fully saturated condition)

$q_{s}=0.25 x \sqrt{\sigma_{c}}$ (Upper bound solution for Gaziantep Limestone, fully saturated condition)

$q_{s}=0.19 x \sqrt{\sigma_{c}}$ (Lower bound solution for Gaziantep Limestone, dry condition)

$q_{s}=0.35 x \sqrt{\sigma_{c}}$ (Upper bound solution for Gaziantep Limestone, dry condition)

\section{CONCLUSIONS}

In this study, the unit side resistance of Gaziantep limestone was investigated experimentally under dry and fully saturated conditions and the results were correlated with the unconfined compressive strength of the corresponding test block. In order to conduct the test program, 24 rock blocks were collected from a rock quarry site in Gaziantep. Each block was divided into two adjacent parts to have a fully saturated and dry sample from each block. As a result, 48 uniaxial compression tests and 48 side resistance tests were performed at the soil mechanics laboratory of Hasan Kalyoncu University. The results have revealed that the reduction of the uniaxial compressive strength of Gaziantep limestone upon full saturation was on the order of $36.10-42.86 \%(\approx 40 \%)$ with respect to the completely dry case. The reduction was also observed for the unit side resistance of Gaziantep limestone upon saturation in a wider range $(23.96-64.23 \%)$.

The unit side resistance value was generally correlated with the uniaxial compressive strength of the corresponding rock in the literature. The methods which recommend a correlation between the unit side resistance and uniaxial compressive strength may be grouped in two broad categories as linear and non-linear correlations. The results of this study were compared with selected linear and non-linear correlations.

The comparison with the linear relationships has revealed that the unit side resistance of Gaziantep limestone was significantly overestimated by the linear correlations for both dry and fully saturated conditions. This fact was also mentioned by other studies conducted on similar rock types. Alternatively, a new linear correlation was suggested for Gaziantep limestone.

The non-linear methods used in the evaluation of the test results of this study have generally provided a reasonable estimation for dry conditions. But these methods, in general, overestimated the unit side resistance values for fully saturated conditions except for the lower bound solution of [11]. Alternatively, non-linear lower and upper bound solutions were suggested in this study as a range for estimating the unit side resistance of Gaziantep limestone for fully saturated and dry conditions.

Based on the findings of this study it may be concluded that the non-linear correlations mentioned in this study were noticeably better in estimating the unit side resistance of Gaziantep limestone as compared to considered linear correlations especially for dry conditions. It should also be emphasized that, since both the uniaxial compressive strength and the unit side resistance of Gaziantep limestone was observed to be significantly reduced 
upon saturation and the measured unit side resistance values were generally overestimated even by the non-linear correlations studied in this research for fully saturated conditions, care should be taken while using these correlations for rock socket design in Gaziantep limestone for places prone to saturation. Alternatively; the lower bound solution of [11] may be utilized for design purposes in such cases. Otherwise, the unit side resistance values may be significantly overestimated resulting in an inadequate design.

It should also be noted that, the unit side resistance of rocks is generally measured by large scale load tests. In this study, an unconfined compression testing machine was modified to measure unit side resistance values in laboratory scale. So, the results presented within this study may be regarded as a primary evaluation for the utilized testing equipment and method. Although the test procedure needs to be improved by further studies, the results are evaluated to be promising since the obtained results and trends were comparable by the previous researches. Future studies should be concentrated on improving the testing method which is expected to significantly facilitate measurement of the unit side resistance as compared to large scale load tests since the test is executed in laboratory scale. Although the scale effects are thought to be negligible since the unit side resistance is investigated and neither concrete nor rock is expected to be affected from the utilized sample dimensions, the results may be compared by large scale load tests on the same rock in future studies.

\section{Symbols}
A Linear correlation coefficient
b Non-linear correlation coefficient
C Non-linear correlation constant
D Sample diameter
$\mathrm{D}_{\mathrm{h}} \quad$ Hole diameter
$\mathrm{D}_{\mathrm{IC}} \quad$ Infilled concrete core diameter
$\mathrm{D}_{\mathrm{LP}} \quad$ Loading piston diameter
F Axial load
$\mathrm{H} \quad$ Sample height
n Porosity
$\mathrm{q}_{\mathrm{s}} \quad$ Unit side resistance of rock
W Water absorption capacity
$\gamma_{\text {dry }} \quad$ Dry unit weight
$\gamma_{\text {sat }} \quad$ Saturated unit weight
$\sigma_{\mathrm{c}} \quad$ Uniaxial compressive strength of rock
$\Delta \quad$ Slip displacement 


\section{References}

[1] Kaderabek, T.J., Reynolds, R.T., Miami limestone foundation design and construction. Journal of Geotechnical and Geoenvironmental Engineering, 107, 1981.

[2] Gupton, C., Logan, T., Design guidelines for drilled shafts in weak rocks of south Florida. South Florida Annual ASCE Meeting, Florida, 1984.

[3] Reese, L.C., O’Neill, M.W., Drilled shafts: Construction and design. FHWA, Publication No. HI-88, 42, 1988.

[4] Toh, C.T., Ooi, T.A., Chiu, H.K., Chee, S.K., Ting, W.H., Design parameters for bored piles in a weathered sedimentary formation. Proc. 12th Int. Conf. Soil Mech. Found. Engng 2, Rio de Janeiro, 1989.

[5] Rosenberg, P., Journeaux, N.L., Friction and end bearing tests on bedrock for high capacity socket design. Canadian Geotechnical Journal, 13(3), 324-333, 1976.

[6] Meigh, A.C., Wolski, W., Design parameters for weak rocks. 7th European Conference on Soil Mechanics and Foundation Engineering, Mexico, 1969.

[7] Horvath, R.G., Kenney, T.C., Shaft resistance of rock-socketed drilled piers. Symposium on Deep Foundations, Atlanta, 1979.

[8] Horvath, R.G., Kenney. T.C., Kozicki, P., Methods of improving the performance of drilled piers in weak rock. Canadian Geotechnical Journal 20(4), 758-772, 1983.

[9] Rowe, R.K., Armitage, H.H., The design of piles socketed into weak rock. University of Western Ontario Faculty of Engineering Science, 1984.

[10] Carter, J.P., Kulhawy, F.H., Analysis and design of drilled shaft foundations socketed into rock (No. EPRI-EL-5918). Electric Power Research Inst., Palo Alto, CA (USA); Cornell Univ., Ithaca, NY (USA). Geotechnical Engineering Group, 1988.

[11] Kulhawy, F.H., Phoon, K.K., Drilled shaft side resistance in clay soil to rock. Design and performance of deep foundations: Piles and piers in soil and soft rock, Texas, 1993.

[12] Rezazadeh, S., Eslami, A., Empirical methods for determining shaft bearing capacity of semi-deep foundations socketed in rocks. Journal of Rock Mechanics and Geotechnical Engineering, 9(6), 1140-1151, 2017.

[13] Rowe, R.K., Armitage, H.H., A design method for drilled piers in soft rock. Canadian Geotechnical Journal, 24(1), 126-142, 1987.

[14] O’Neill, M.W., Reese, L.C., Drilled Shafts: Construction Procedures and Design. Report FHWA-IF-99-025, Federal Highway Administration, Virginia, 1999.

[15] Akgüner, C., Kirkit, M., Kayaya Soketli Kazıkların Yükleme Deneyi ve Ampirik Yöntemlerle Belirlenen Kapasitelerinin Karşılaştırılması. Teknik Dergi, 22(109), 5713-5723, 2011.

[16] Marangoz, L., Correlation of geotechnical properties of limestone with ultrasonic pulse velocity in Gaziantep region. M.Sc. thesis submitted to School of Natural and Applied Science, University of Gaziantep, 2005. 
[17] Canakci, H., Collapse of caves at shallow depth in Gaziantep city center, Turkey: a case study. Environmental geology, 53(4), 915-922, 2007.

[18] Xie, S. Y., Shao, J. F., Elastoplastic deformation of a porous rock and water interaction. International Journal of Plasticity, 22(12), 2195-2225, 2006.

[19] International Society for Rock Mechanics, The complete ISRM suggested methods for rock characterization, testing and monitoring: 1974-2006. International Soc. for Rock Mechanics, Commission on Testing Methods, 2007.

[20] ASTM C39 / C39M-18, Standard Test Method for Compressive Strength of Cylindrical Concrete Specimens. ASTM International, West Conshohocken, PA, 2018.

[21] Carter, J.P., Kulhawy, F.H., Analysis of laterally loaded shafts in rock. Journal of Geotechnical Engineering, 118(6), 839-855, 1992.

[22] Kulhawy, F.H., Akbas, S.O., Prakoso, W.A., Evaluation of capacity of rock foundation sockets, the 40th US Symposium on Rock Mechanics (USRMS) of American Rock Mechanics Association, Alaska, 2005.

[23] Salgado, R., The engineering of foundations, New York. McGraw-Hill, 2008.

[24] Williams, A.F., Johnston, J.W., Donald, I.B., Design of socketed piled in weak rock. In: Proceedings of international conference on structural foundations on rock, 327-347, 1980.

[25] Williams, A., Pells, P. J. N., Side resistance rock sockets in sandstone, mudstone, and shale. Canadian Geotechnical Journal, 18(4), 502-513, 1981.

[26] Bloomquist, D., Townsend, F. C., Development of insitu equipment for capacity determinations of deep foundations in Florida limestone. University of Florida, Department of Civil Engineering, 1991.

[27] McVay, M. C., Townsend, F. C., Williams, R. C., Design of socketed drilled shafts in limestone. Journal of geotechnical engineering, 118(10), 1626-1637, 1992.

[28] AASHTO, AASHTO LRFD bridge design specifications. Transportation (Amst). American Association of State Highway and Transportation Officials, Inc., Washington, DC, 2007.

[29] CFEM, Canadian foundation engineering manual $4^{\text {th }}$ edition. Canadian Geotechnical Society, 2006. 